University of Nebraska - Lincoln

DigitalCommons@University of Nebraska - Lincoln

U.S. Department of Veterans Affairs Staff

Publications

U.S. Department of Veterans Affairs

2011

\title{
Impact of statin use on heart failure mortality
}

Senthil K. Thambidorai

Creighton University, skt73723@creighton.edu

Anand R. Deshmukh

Creighton University, drananddeshmukh@yahoo.com

Ryan W. Walters

Creighton University, ryanwalters@creighton.edu

Paul D. Turner

Creighton University, paulturner@creighton.edu

Michael S. Monaghan

Creighton University, msmonagh@creighton.edu

See next page for additional authors

Follow this and additional works at: https://digitalcommons.unl.edu/veterans

Thambidorai, Senthil K.; Deshmukh, Anand R.; Walters, Ryan W.; Turner, Paul D.; Monaghan, Michael S.; Mooss, Aryan N.; Hunter, Claire B.; Esterbrooks, Dennis J.; and Mohiuddin, Syed M., "Impact of statin use on heart failure mortality" (2011). U.S. Department of Veterans Affairs Staff Publications. 80.

https://digitalcommons.unl.edu/veterans/80

This Article is brought to you for free and open access by the U.S. Department of Veterans Affairs at DigitalCommons@University of Nebraska - Lincoln. It has been accepted for inclusion in U.S. Department of Veterans Affairs Staff Publications by an authorized administrator of DigitalCommons@University of Nebraska - Lincoln. 


\section{Authors}

Senthil K. Thambidorai, Anand R. Deshmukh, Ryan W. Walters, Paul D. Turner, Michael S. Monaghan, Aryan N. Mooss, Claire B. Hunter, Dennis J. Esterbrooks, and Syed M. Mohiuddin 


\title{
Impact of statin use on heart failure mortality
}

\author{
Senthil K. Thambidorai a,b,*, Anand R. Deshmukh ${ }^{\mathrm{a}, \mathrm{b}}$, Ryan W. Walters ${ }^{\mathrm{c}}$, Paul D. Turner ${ }^{\mathrm{c}}$, \\ Michael S. Monaghan ${ }^{\text {d }}$, Aryan N. Mooss ${ }^{\mathrm{a}}$, Claire B. Hunter ${ }^{\mathrm{a}}$, Dennis J. Esterbrooks ${ }^{\mathrm{a}}$, Syed M. Mohiuddin ${ }^{\mathrm{a}, \mathrm{c}, \mathrm{d}}$ \\ a Department of Cardiovascular Medicine, Creighton University, Omaha, NE, USA \\ ${ }^{\mathrm{b}}$ Department of Internal Medicine, Veterans Affairs - Nebraska Western Iowa Health Care System, Omaha, NE, USA \\ c Department of Internal Medicine, Creighton University, Omaha, NE, USA \\ d Department of Pharmacy Practice, Creighton University, Omaha, NE, USA
}

\section{A R T I C L E I N F O}

Article history:

Received 30 October 2009

Received in revised form 18 May 2010

Accepted 8 August 2010

Available online 23 October 2010

\section{Keywords:}

Statins

Heart failure

Mortality

\begin{abstract}
A B S T R A C T
Background: There is conflicting data regarding the mortality benefit of statins in patients with heart failure. The objectives of our study were to determine whether statin therapy is associated with decreased all-cause mortality and to assess the effect of incremental duration of therapy.

Methods: We studied 10,510 consecutive patients from the Veterans Affairs health system with a diagnosis of heart failure from January 2002 through December 2006. Mean follow-up was 2.66 years. Statin use and duration of therapy were identified. Veterans were classified into four groups based on duration of statin use during the study period (none, $1-25 \%, 26-75 \%$ and $>75 \%$ use of statins). Logistic regression was performed to identify the association between incident statin use and all-cause mortality following a diagnosis of heart failure. The Kaplan-Meier method was employed to assess for differences in survival time between the four statin use classifications.

Results: Statin use was significantly associated with decreased all-cause mortality following a diagnosis of heart failure after controlling for age, gender, concurrent medications and comorbid diagnoses $\left[\chi_{3}^{2}\right.$ $(\mathrm{N}=10,510)=1077.82, \mathrm{p}<0.001]$. The benefit was seen within a relatively short duration (within 1 year) after starting statins, and in patients with $<25 \%$ use of statins, there was no mortality benefit. Conclusion: Veterans who were not exposed to statin therapy at any time during the study period were 1.56 times more likely to suffer all-cause mortality.
\end{abstract}

(c) 2010 Elsevier Ireland Ltd. All rights reserved.

\section{Background}

Large randomized trials on statins have excluded patients with heart failure. It is well-known that statins effectively lower lowdensity lipoprotein levels. But there is increasing evidence of "pleiotropic" effect of statins that could affect the outcome in heart failure patients. At molecular level, statins are associated with both beneficial and harmful effects. Heart failure is associated with evidence of systemic inflammation, which is evident in the form of increase in proinflammatory markers such as interleukin-6, tumor necrosis factors and C-reactive protein. Statins decrease these proinflammatory markers $[1,2]$. Statins decrease the free radical production, which have been suggested to have causal role in development of heart failure [3]. Statins increase nitric oxide production by stimulation of endothelial nitric oxide synthase, which has been linked to myocardial perfusion, vasodilatation, and LV remodeling [4]. Statins decrease myocyte hypertrophy, attenuate LV remodeling and myocardial fibrosis $[5,6]$. Treatment with statins is

\footnotetext{
* Corresponding author. Department of Cardiovascular Medicine, Creighton Univer-
} sity, 3006 Webster Street, Omaha, NE 68131, USA. Tel.: +1 4022804626; fax: +1 associated with decreased angiotensin I mediated vasoconstriction, enhanced response to angiotensin receptor blockage drugs [7]. Statins are associated with decreased incidence of atrial fibrillation, ventricular arrhythmias, or sudden cardiac death $[8,9]$.

There are potential harmful effects of statins. These include decrease in circulating cholesterol and triglyceride rich lipoproteins, which have the ability to detoxify endotoxins [10]. Statin causes reductions in levels of coenzyme Q10, which has been linked to protection from free radical injury [11]. It also decreases selenoprotein levels that could lead to skeletal and cardiac myopathy [12].

There is conflicting evidence regarding the benefit of statins in patients with congestive heart failure [13-20]. The main limitation of large databases is that statin therapy was recorded at a single time of the study, mostly on discharge diagnosis. As shown in the myocardial infarction trials with statin, the mortality increases in patients when statins are discontinued [21].

CORONA study has raised doubts on the effects of statins on heart failure patients, but the study population consisted of elderly patients with only ischemic heart failure, where the disease might have been too advanced to modify [22]. Compliance with statin therapy has been a major confounder in the observational studies and GISSI-HF randomized controlled trial [23]. Both randomized control trials have 
evaluated the effect of one type of statin (rosuvastatin) on heart failure and there is no conclusive evidence of a class effect of statins [24]. With all the available evidence, further studies are needed to determine the effect of statins in patients with heart failure.

The primary objective of our study was to evaluate the effect of statins on mortality in a large group of patients with heart failure in a usual care setting. The secondary objective was to evaluate the incremental duration of statin therapy on mortality in heart failure.

\section{Methods}

\subsection{Study design and sample}

A retrospective cohort design was used to examine veterans diagnosed with heart failure during the five-year period from January 1, 2002 through December 31, 2006 using administrative data abstracted from the Veterans Affairs Midwest Health Care Network (Veterans Integrated Service Network, VISN 23). (Deleted local details of the VA network as per reviewer's request along with previous reference number 25 from the initial manuscript).

\subsection{Inclusion criteria}

Veterans were included in the study if they met the following criteria: 20 years of age or older and one or more hospitalizations with either a primary or secondary diagnosis of heart failure (ICD-9-CM codes of 398.91, 402.01, 402.11, 402.91, 428.0, 428.1 , or 428.9 ) or a primary diagnosis of heart failure during an outpatient visit. The heart failure index date (HF-ID) was defined as the first diagnosis of heart failure (HF) and one previous outpatient/inpatient visit with no primary or secondary diagnosis of HF.

\subsection{Exclusion criteria}

Veterans who were censored within 180 days of heart failure diagnosis were excluded from the study (i.e., the veteran must have remained alive 180 days following heart failure diagnosis, with diagnosis prior to July 5,2006 ).

A total of 10,510 veterans met the inclusion criteria. However, the date of statin therapy initiation was unknown in some patients with heart failure. We identified a cohort of 5282 veterans with heart failure who initiated statin therapy after their respective HF-ID. This cohort did not receive any statin therapy for at least 120 days prior to HF-ID. A subsequent subgroup analysis was performed to eliminate the bias of previous statin therapy on the outcome in patients with heart failure. The study flow is represented in Fig. 1.

The demographic and health care information over the five-year period for this cohort of veterans was exported into a database created specifically for the study. The data were obtained from the VISN 23 Data Warehouse using the VA Computerized Patient Record System (CPRS). CPRS contains all components of a patient's medical records including but not limited to demographic information (including mortality date), clinical procedures, laboratory and diagnostic test results, decision support, pharmaceutical utilization (bar code medication administration), progress notes, appointments, International Classification of Diseases-Ninth Revision-Clinical Modification (ICD-9-CM) codes for diagnoses and procedures, and Diagnosis Related Groups (DRGs).

\subsection{Stratification of statin use}

Statin use was defined as filling one or more statin prescription (i.e., fluvastatin, lovastatin, pravastatin, simvastatin, atorvastatin, or rosuvastatin) during the 3 months prior to HF-ID (e.g., October 1, 2001 for an HF-ID of January 1, 2002) or anytime thereafter up to the study end date of December 31, 2006. Pharmacy refill data were abstracted from the VA Decision Support System (DSS) National Data Extract (NDE) SAS Datasets and included both inpatient and outpatient prescriptions dispensed by a VA Medical Center Pharmacy or a Veterans Affairs Consolidated Mail Outpatient

Statin use (start date not available)

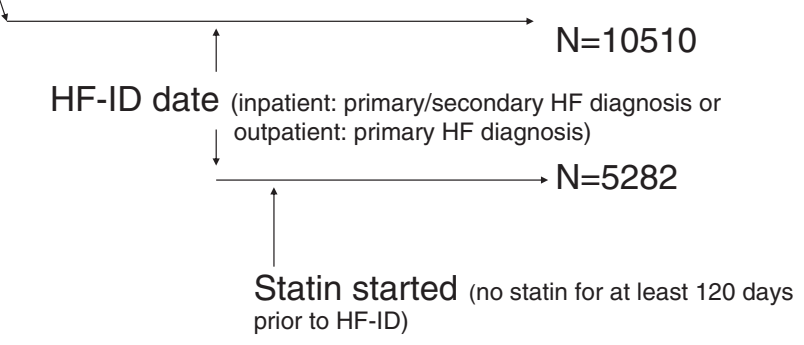

Fig. 1. Study flow.
Pharmacy (CMOP) [25]. (Changed reference number due to deletion of previous reference number 25$)$.

Longitudinal statin use was estimated as the percentage of time quantified from refill patterns based on refill dates and quantity/supply. The maximum number of days a veteran could remain on statin therapy was calculated as the number of days from therapy initiation until end of follow up (i.e., December 31, 2006) or death. The total number of days the veteran was not on a statin was then subtracted, and this difference was divided by the maximum number of days and multiplied by 100 , yielding the percentage of statin use following initiation of statin therapy during the study period. Individuals were then stratified exclusively into one of four possible groups: Nonusers (no statin prescription filled between October 1, 2001 and December 31, 2006), $\leq 25 \%$, $>25 \%$ to $75 \%$ statin use and $>75 \%$ statin use.

\subsection{Covariates}

Date of birth, race, and gender were abstracted from the CPRS. Forty-eight percent of the race data were missing and preliminary assessment indicated the data were missing not at random (MNAR) precluding the option of replacing the missing data through traditional approaches (i.e., imputation or maximum likelihood estimate modeling) [26,27]. Thus, race was dropped from analyses, resulting in gender and age at HF-ID as the demographic covariates. Comorbid conditions were identified from diagnoses using ICD-9 codes as either a principal or secondary diagnosis of coronary heart disease, atrial fibrillation, cerebrovascular disease, hemorrhagic stroke, connective tissue disease, diabetes, hypertension, coronary artery disease, hyperlipidemia, depression, chronic kidney disease, liver disease, lung disease, malignancies, peripheral arterial disease, peptic ulcer disease, HIV, dementia, and sudden cardiac death. Concurrent cardioprotective medications were controlled for during the 3 months prior to January 1, 2002 and anytime thereafter up to the study end date of December 31, 2006. These medications included beta blockers, angiotensin converting enzyme (ACE) inhibitors, angiotensin receptor blockers (ARB), aspirin (ASA), and spironolactone. The method of using prescription refill and quantity/supply data to calculate percentage of concurrent medication use for individual medications was analogous to statin use described above, except these percentages were not stratified but rather analyzed as continuous variables.

\section{Statistical analysis}

Statistical analysis was performed using SPSS 15.0 (SPSS Inc, Chicago, IL). Continuous variables are presented as mean \pm SD and categorical variables are presented as numbers (\%). We compared descriptive characteristics among all veterans included in the study period using the Kruskal-Wallis test for continuous data and the chisquare test for nominal data. A two-sided p value of less than 0.05 indicated significance for omnibus tests. When necessary, post hoc tests (i.e., the Mann-Whitney test for continuous data and Fisher's exact test for categorical data) were conducted employing a Bonferroni adjustment to control for multiple comparisons; thus, significant post hoc tests were indicated by a two-sided $\mathrm{p}$ value less than 0.008 .

The survival function for each statin use stratification was summarized using the Kaplan-Meier method. For the omnibus logrank test, a two-sided $\mathrm{p}$ value less than 0.05 indicated statistical significance. Pairwise comparisons, using a Bonferroni adjustment, were employed to identify group differences, with a two-sided $p$ value of 0.008 indicating statistical significance. At the end of the study period, sequential logistic regression was used to model all-cause mortality by the four statin use stratifications controlling for the covariates described previously.

\section{Results}

A total of 10,510 veterans with heart failure were identified during the five-year study period from January 1, 2002 through December 31, 2006. This cohort was predominantly male $(98.4 \%)$ with a mean age of 72.0 years and an all-cause mortality rate of $25.8 \%$. The average individual had a mean of 973.4 days ( 2.66 years) in the study post HF-ID, was on two cardioprotective medications, and had four comorbid conditions. Statin therapy was initiated in $71.0 \%$ of these veterans.

Statin users were further stratified by the percentage of time they remained on statin therapy during the study period, as described previously. Descriptive statistics for this cohort are displayed in Table 1. Post hoc tests indicated statin nonusers were older and had higher mortality rates in comparison to statin users $(\mathrm{p}<0.001$ for each stratification respectively). Further, statin nonusers were less likely to be on concurrent medications compared to veterans who remained on statin therapy $>25 \%$ of the time during the study period ( $\mathrm{p}<0.001$ for all comparisons). Statin nonusers were less likely to have a comorbid diagnosis of coronary artery disease, hyperlipidemia, and 
Table 1

Descriptive characteristics stratified by percentage of time on statin following initiation of statin therapy $(N=10,510)$.

\begin{tabular}{|c|c|c|c|c|c|}
\hline \multirow[t]{3}{*}{ Variable } & \multicolumn{4}{|l|}{ Statin use } & \multirow[t]{3}{*}{ p value } \\
\hline & \multirow{2}{*}{$\begin{array}{l}\text { None } \\
(n=3044)\end{array}$} & \multirow{2}{*}{$\begin{array}{l}>0 \text { to } 25 \% \\
(n=234)\end{array}$} & \multirow{2}{*}{$\frac{>25 \text { to } 75 \%}{(n=1086)}$} & \multirow{2}{*}{$\frac{>75 \%}{(n=6146)}$} & \\
\hline & & & & & \\
\hline Age at HF diagnosis (years) & $73.57 \pm 11.38$ & $71.39 \pm 10.44$ & $68.86 \pm 10.70$ & $71.79 \pm 9.50$ & $<0.001$ \\
\hline Follow-up time (days) ${ }^{\dagger}$ & $919.37 \pm 504.18$ & $982.58 \pm 497.54$ & $967.03 \pm 506.87$ & $1000.87 \pm 494.56$ & $<0.001$ \\
\hline Male & 2981 (97.9\%) & $228(97.4 \%)$ & 1063 (97.9\%) & $6072(98.8 \%)$ & 0.003 \\
\hline All-cause mortality & $1135(37.3 \%)$ & $54(23.1 \%)$ & $203(18.7 \%)$ & $1315(21.4 \%)$ & $<0.001$ \\
\hline \multicolumn{6}{|l|}{ Medications $s^{\ddagger}$} \\
\hline ACE inhibitor & $85.34 \pm 24.56$ & $77.11 \pm 31.44$ & $80.38 \pm 24.05$ & $88.83 \pm 20.27$ & $<0.001$ \\
\hline ARB & $86.40 \pm 23.85$ & $78.05 \pm 34.12$ & $84.91 \pm 19.20$ & $85.91 \pm 23.97$ & $<0.001$ \\
\hline ASA & $73.23 \pm 32.03$ & $60.07 \pm 34.11$ & $69.21 \pm 32.11$ & $78.28 \pm 29.47$ & $<0.001$ \\
\hline Beta blocker & $84.32 \pm 24.04$ & $74.78 \pm 30.77$ & $81.05 \pm 21.64$ & $89.50 \pm 17.76$ & $<0.001$ \\
\hline Spironolactone & $83.07 \pm 25.42$ & $75.37 \pm 31.70$ & $79.74 \pm 26.69$ & $83.65 \pm 26.64$ & $<0.001$ \\
\hline \multicolumn{6}{|l|}{ Comorbid conditions } \\
\hline Atrial fibrillation & $1125(37.0 \%)$ & $84(35.9 \%)$ & $337(31.0 \%)$ & $2141(34.8 \%)$ & 0.005 \\
\hline Cerebrovascular disease & $329(10.8 \%)$ & $30(12.8 \%)$ & $113(10.4 \%)$ & $603(9.8 \%)$ & 0.258 \\
\hline Connective tissue disease & $113(3.7 \%)$ & $8(3.4 \%)$ & $42(3.9 \%)$ & 285 (4.6\%) & 0.158 \\
\hline Coronary heart disease & $1331(43.7 \%)$ & $154(65.8 \%)$ & $771(71.0 \%)$ & $4571(74.4 \%)$ & $<0.001$ \\
\hline Dementia & 217 (7.1\%) & $12(5.1 \%)$ & $41(3.8 \%)$ & 247 (4.0\%) & $<0.001$ \\
\hline Depression & $508(16.7 \%)$ & $38(16.2 \%)$ & $204(18.8 \%)$ & $1097(17.8 \%)$ & 0.340 \\
\hline Diabetes & $901(29.6 \%)$ & $86(36.8 \%)$ & $489(45.0 \%)$ & $2743(44.6 \%)$ & $<0.001$ \\
\hline Hemorrhagic stroke & $11(0.4 \%)$ & $0(0.0 \%)$ & $2(0.2 \%)$ & $14(0.2 \%)$ & 0.507 \\
\hline HIV & $1(0.0 \%)$ & $0(0.0 \%)$ & $1(0.1 \%)$ & $2(0.0 \%)$ & 0.803 \\
\hline Hyperlipidemia & $752(24.7 \%)$ & $153(65.4 \%)$ & $871(80.2 \%)$ & $5069(82.5 \%)$ & $<0.001$ \\
\hline Hypertension & $2069(68.0 \%)$ & $179(76.5 \%)$ & $861(79.3 \%)$ & $4985(81.1 \%)$ & $<0.001$ \\
\hline Kidney disease & $233(7.7 \%)$ & $24(10.3 \%)$ & $85(7.8 \%)$ & $458(7.5 \%)$ & 0.452 \\
\hline Liver disease & $94(3.1 \%)$ & $5(2.1 \%)$ & $9(0.8 \%)$ & 57 (0.9\%) & $<0.001$ \\
\hline Lung disease & $1265(41.6 \%)$ & $93(39.7 \%)$ & $434(40.0 \%)$ & $2339(38.1 \%)$ & 0.013 \\
\hline Malignancy & $484(15.9 \%)$ & 35 (15.0\%) & $142(13.1 \%)$ & $813(13.2 \%)$ & 0.004 \\
\hline Peptic ulcer disease & $91(3.0 \%)$ & $5(2.1 \%)$ & $37(3.4 \%)$ & $159(2.6 \%)$ & 0.350 \\
\hline $\begin{array}{l}\text { Peripheral } \\
\text { arterial disease }\end{array}$ & 307 (10.1\%) & $34(14.5 \%)$ & $178(16.4 \%)$ & $1004(16.3 \%)$ & $<0.001$ \\
\hline Sudden cardiac death & $0(0.0 \%)$ & $0(0.0 \%)$ & $0(0.0 \%)$ & $1(0.0 \%)$ & 0.871 \\
\hline
\end{tabular}

Data are presented as mean \pm SD or numbers (\%).

$\mathrm{ACE}=$ angiotensin converting enzyme inhibitors; $\mathrm{ARB}=$ angiotensin receptor blockers; $\mathrm{ASA}=$ acetylsalicylic acid; $\mathrm{HF}=$ heart failure; HIV $=$ human immunodeficiency virus.

* p values for omnibus tests across the 4 groups.

Number of days in study following heart failure diagnosis.

* Number of veterans on each medication differed by statin use stratification.

hypertension in comparison to all statin use stratifications (all $\mathrm{p}<0.001$ ). However, statin nonusers were more likely to have a diagnosis of atrial fibrillation, lung disease, and malignancy compared to patients remaining on statin therapy (all $\mathrm{p}<0.001$ ).

Duration of statin use as a predictor of all-cause mortality: The Kaplan-Meier method was employed to assess for differences in survival time following a diagnosis of heart failure between the four statin use stratifications. The omnibus Mantel-Cox logrank test indicated significant differences in survival time $\left(\chi_{3}^{2}=307.2, \mathrm{p}<0.001\right.$; Fig. 2$)$. Analysis of pairwise comparisons indicated survival time for veterans who did not initiate statin therapy during the study period was significantly shorter in comparison to statin users, regardless of the percentage of time on statin (all $\mathrm{p}<0.001$ ).

Sequential logistic regression was performed to identify the association between duration of statin use and all-cause mortality among veterans with heart failure controlling for age, gender, concurrent medications, and comorbid conditions described above. Evaluation of adequacy of expected frequencies for categorical covariates revealed no need to restrict model goodness-of-fit tests and no serious violation of linearity of the logit was observed.

The addition of the statin use stratifications to the logistic model significantly improved prediction of all-cause mortality $\left(\chi_{3}^{2}=87.7, \mathrm{p}<0.001\right)$. Overall, the results indicated the variables, as a set, are significantly associated with all-cause mortality $\left(\chi_{3}^{2}=1078.1, \mathrm{p}<0.001\right)$; however, the variance in mortality accounted for by the model is small (Nagelkerke $\mathrm{R}^{2}=0.143$, with a $95 \%$ confidence interval for the effect size ranging from 0.121 to 0.157 ) [28]. Table 2 displays the logistic regression results.

Veterans who were not exposed to statin therapy at any time during the study period were 1.56 times more likely to suffer all-cause mortality. In addition, veterans who were exposed to $>25 \%$ statin use during the study period were more likely to remain alive, following a diagnosis of heart failure.

Effect of statin use post HF-ID: We identified a cohort of 5282 veterans with heart failure diagnosis who were presumably started on statin therapy after the HF-ID to assess for difference in survival time among four statin use stratifications. This subgroup analysis was conducted to eliminate the bias of the unknown duration of statin therapy prior to heart failure diagnosis. The demographic and medication use of this cohort was similar to the original cohort (see Appendix A). Kaplan-Meier analysis was done and the omnibus Mantel-Cox log-rank test indicated significant differences in survival time $\left(\chi_{3}^{2}=259.27, \mathrm{p}<0.001\right.$; Fig. 3 ). Analysis of pairwise comparisons employing the logrank test indicated survival time for veterans who did not initiate statin therapy was significantly shorter in comparison to three other groups of statin users ( all $\mathrm{p}<0.001$ ).
Logistic regression was performed on the cohort of 5282 veterans to identify the association between incident statin use and all-cause mortality following diagnosis of heart failure. No assumption violations were indicated. Similar to the results from the previous cohort, the addition of the statin use stratifications to the model significantly improved prediction of all-cause mortality $\left(\chi_{3}^{2}=63.62, \mathrm{p}<0.001\right)$. Further the variables as a set with mortality $\left(\chi_{28}^{2}=661.25, \mathrm{p}<0.001\right)$. The current model explains a larger percentage of the variance in mortality than the original cohort (Nagelkerke $\mathrm{R}^{2}=0.167$ with $95 \%$ confidence limits from 0.144 to 0.182 ). The results of logistic regression are presented in Table 3.

The results from this subgroup analysis indicated veterans who were not exposed to statin therapy were 1.54 times more likely to suffer all-cause mortality. Veterans who initiated statin therapy after the diagnosis of heart failure and maintained it for $>25 \%$ of the duration of the study period were more likely to remain alive, following a diagnosis of heart failure. However, incremental benefit was not seen in $>25 \%$ of statin use similar to original cohort.

\section{Discussion}

The main findings of the study were that: [1] Statins decrease allcause mortality in this elderly heart failure population, [2] statin therapy initiation and continuation for $>25 \%$ of the duration after a diagnosis of heart failure decreased all-cause mortality over a mean follow-up period of 2.66 years.

The mean age of patients in our study was 72 years compared to 73 years in the

CORONA study and 68 years in GISSI-HF study. The mortality rate in our study cohort was $25.8 \%$, which is similar to the mortality rate in GISSI-HF study (29\%), but higher than mortality rate in CORONA study (11.6\%) [22,23]. Our study, similar to GISSI-HF study evaluated the effect of statins in both ischemic and nonischemic heart failure. The reasons for differences in the mortality rates compared to CORONA study are unclear, but could be due to differences in revascularization 


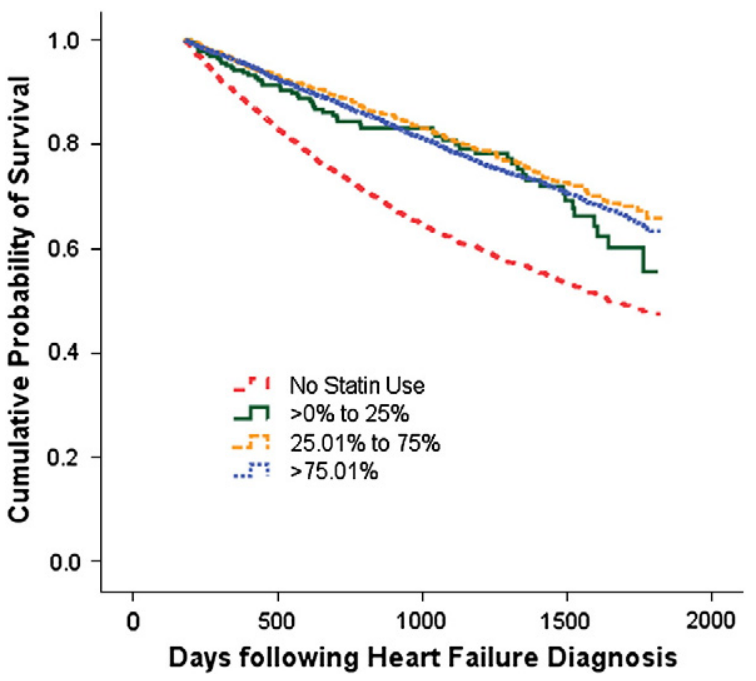

Fig. 2. Unadjusted survival function stratified by percentage of time on statin following initiation of statin therapy $(\mathrm{N}=10,510)$.

rates, aggressive lipid control and other co-morbidities. The effect of cardioprotective medications could have been more substantial in patients with ischemic heart failure as opposed to patients with nonischemic heart failure. This could also explain the reason for the lack of additional benefit seen with statins in the CORONA study. Our study had mortality rates similar to that seen in the heart failure population of the Framingham study, underscoring the fact that the VA represents a large diverse population [29].

Several trials have been published to date that have evaluated the effect of statins on incidence of heart failure and mortality [13-20]. Most of the data evaluating the effect of statins on heart failure has been obtained from retrospective analyses of clinical trials. Treatment with statins consistently resulted in significant decrease in mortality across multiple clinical trials. The main limitation of these large databases is that statin therapy was recorded at single time in the study, mostly at discharge diagnosis. Considering the high prevalence of ischemic heart disease, the beneficial effect of statins in these trials was attributed to reduction in the incidence of ischemic complications. However, few prospective trials have also studied the effect of statins on patients with non ischemic cardiomyopathy and showed improvement in symptoms $[13,16,17]$ and improvement in mortality $[18,19]$. Previous retrospective studies have largely focused on selected subgroups of patients with heart failure. Moreover there were lack of serial cross sectional data on statin exposure, smaller sample sizes and incomplete adjustments for the effects of concurrent treatments and their compliance. Our patient population was large with multiple comorbidites among 5 different states in the Midwest with equal access to care. All the patients at the Veterans Healthcare System receive lipid lowering therapy based on national guidelines. Medication compliance is an important factor in consideration of the treatment of patients with heart failure. We evaluated all the patients based on the duration of use of statins during the study period. To our

Table 2

Results of adjusted logistic model for primary analysis $(\mathrm{N}=10,510)$.

\begin{tabular}{lrllllll}
\hline Statin use & \multicolumn{1}{l}{$\mathrm{n}$} & $\mathrm{B}$ & $\mathrm{SE}$ & $\mathrm{OR}$ & \multicolumn{2}{l}{$95 \% \mathrm{Cl}$} & $\mathrm{p}$ \\
\cline { 6 - 7 } & & & & & Lower & Upper & \\
\hline None & 3044 & 0.445 & 0.060 & 1.561 & 1.389 & 1.755 & 0.000 \\
$>0$ to $25 \%$ & 234 & -0.122 & 1.230 & 0.885 & 0.695 & 1.128 & 0.324 \\
$>25$ to $75 \%$ & 1086 & -0.213 & 0.075 & 0.808 & 0.698 & 0.936 & 0.004 \\
$>75 \%$ & 6146 & -0.111 & 0.054 & 0.895 & 0.805 & 0.995 & 0.040 \\
\hline
\end{tabular}

$\mathrm{N}$ - total number of patients in all the groups, $\mathrm{n}$ - number of patients in each statin group, B - coefficient, SE - standard error, OR - odds ratio, CI - confidence interval, $\mathrm{p}-\mathrm{p}$ value.

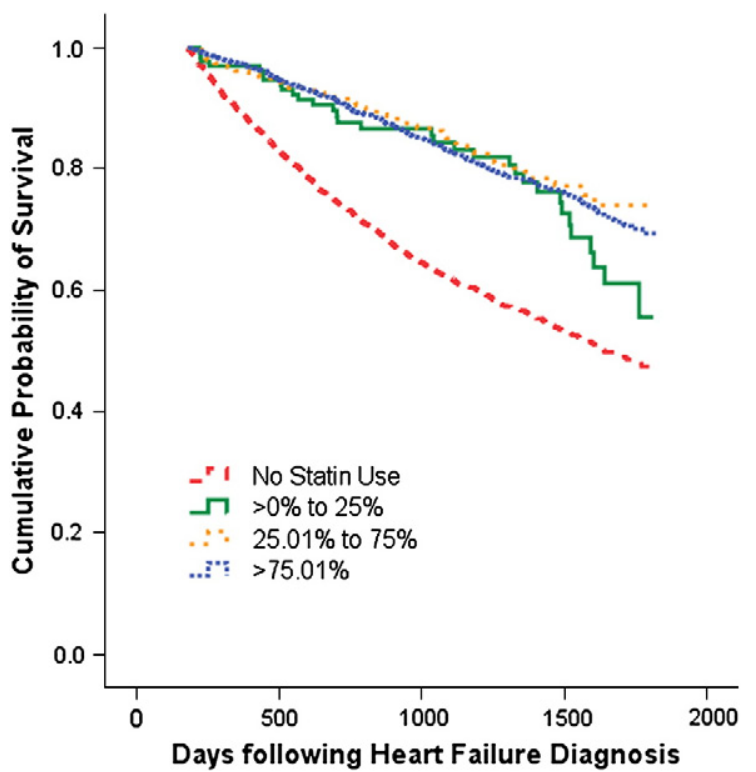

Fig. 3. Unadjusted survival function stratified by percentage of time on statin for veterans only initiating statin therapy following heart failure diagnosis $(\mathrm{N}=5282)$.

knowledge, this is the first study that looked at the differences in the duration of statin use and all-cause mortality and elucidated that the patient had to be receiving enough to provide power for stratified analysis. We also tried to control for the comorbidites, which could significantly affect the all-cause mortality. All the veterans get their medicines from the Veterans Health Care System either free or at minimal cost, thus all the statin and other cardioprotective drugs were accounted for in our study, including adjusting for concurrent medication usage and the duration of their usage.

CORONA study randomized 5011 patients with NYHA class II to IV heart failure patients [22]. In this trial, treatment with rosuvastatin was not associated with significant improvement in the primary endpoint, which was a composite of death from cardiovascular causes, non fatal myocardial infarction or nonfatal stroke. In this trial, the rate of atherothrombotic events was relatively low in a short duration ( 2.7 years) and majority of deaths were due to worsening HF, which reflects patients with advanced HF. The study included older patients with moderate to severe heart failure who were NYHA functional class III or IV in which the disease was probably too advanced to modify ( $60 \%$ of patients were NYHA III). Thus the primary endpoint may not have captured the beneficial effects of rosuvastatin in this elderly group with advanced HF. There was significant decrease in HF hospitalization (secondary endpoint), which is more related to decreased ischemic episodes. Our study included patients who were captured at the first known diagnosis of heart failure and thus the patients were effectively initiated on a statin when the disease was modifiable. Recent meta-analysis that evaluated 13 studies including CORONA study showed that there was $26 \%$ decrease in relative risk of mortality among statin users, similar to our finding [20].

Table 3

Results of adjusted logistic model for sub-analysis $(\mathrm{N}=5282)$.

\begin{tabular}{lrllllll}
\hline Statin use & $\mathrm{n}$ & $\mathrm{B}$ & $\mathrm{SE}$ & $\mathrm{OR}$ & \multicolumn{2}{l}{$95 \% \mathrm{CI}$} & $\mathrm{p}$ \\
\cline { 5 - 7 } & & & & & Lower & Upper & \\
\hline None & 3044 & 0.434 & 0.077 & 1.543 & 1.328 & 1.793 & 0.000 \\
$>0$ to $25 \%$ & 135 & 0.006 & 0.164 & 1.006 & 0.730 & 1.388 & 0.969 \\
$>25$ to $75 \%$ & 355 & -0.249 & 0.121 & 0.779 & 0.614 & 0.989 & 0.040 \\
$>75 \%$ & 1748 & -0.191 & 0.082 & 0.826 & 0.704 & 0.970 & 0.020
\end{tabular}

$\mathrm{N}$ - total number of patients in all the groups, $\mathrm{n}$ - number of patients in each statin group, B - coefficient, SE - standard error, OR - odds ratio, CI - confidence interval, $\mathrm{p}-\mathrm{p}$ value. 
Compliance with statin therapy is a major confounder in the observational studies and GISSI-HF trial [23]. GISSI-HF study randomized 4574 patients (40\% ischemic, 60\% NYHA II) to treatment with rosuvastatin and placebo. There was no difference in any endpoints and this led them to conclude that statins can be discontinued in HF, if there are no other indications. One of the main limitations in the GISSI-HF study was that $1 / 3$ rd of study patients were not compliant with treatment due to various reasons. As shown in our study, patients who used statin for $<25 \%$ had no benefit and the improvement in mortality was apparent only when the statin was $>25 \%$ of the duration. In the Kaplan-Meier analysis, the patients who used the statin for $<25 \%$ of the time had survival curves approach those with no statin use, during the latter half of the follow-up period (Figs. 2 and 3 ). This was similar to the myocardial infarction trials, where discontinuation of statins increased all-cause mortality [30]. Based on our study, the benefit was seen within a relatively short duration (within 1 year) after starting statins and in patients with $<25 \%$ use of statins, there was no mortality benefit.

CORONA and GISSI-HF trials evaluated the effect of one type of statin use on heart failure and there is no conclusive evidence of class effect of statins. Our study evaluated effects of various types of statins in patients with both ischemic and non ischemic heart failure. Majority of the patients in this study population were on simvastatin (85\%) and atorvastatin (4.5\%). These statins have been specifically associated with improved mortality rates in heart failure patients $[6,14-16,24]$. There has been only one study evaluating the class effect of statins in a large population based study with congestive heart failure, but this did not evaluate rosuvastatin [24].
The lack of incremental benefit between patients with $26-75 \%$ of statin use as opposed to $>75 \%$ of statin use was a surprising finding to us. This could be due to nature of the study or it could mean that effect of statin may reach a plateau after certain period in heart failure patients.

Our study has a few limitations. As a retrospective study, we cannot completely rule out the effect of confounding factors. We could not control for certain prognostic factors such as heart rate, blood pressure, left ventricular ejection fraction and cholesterol levels. In older heart failure patients the ejection fraction plays a lesser role than etiology in predicting overall mortality, as shown in the Framingham study [29]. The study includes veterans, so the predominant population is male sex. Race data were missing in $48 \%$ of patients in non random fashion.

In conclusion, our study showed statin use was significantly associated with decrease in all-cause mortality following the diagnosis of heart failure. Patients who were not exposed to statin therapy were 1.56 times more likely to suffer all-cause mortality during the follow up of 2.66 years. This is the first study to our knowledge evaluating the graded relation between statin use and mortality in heart failure patients.

\section{Acknowledgements}

We would like to thank Stephanie R. Maciejewski, Pharm.D, for her help with the study. Dr. Thambidorai received funding from the VA Chronic Heart Failure Quality Enhancement Research Initiative.

The authors of this manuscript have certified that they comply with the principles of ethical publishing in the International Journal of Cardiology [31].

\section{Appendix A}

Table S1

Descriptive characteristics of veterans initiating statin use post HF-ID $(\mathrm{N}=5282)$.

\begin{tabular}{|c|c|c|c|c|c|}
\hline \multirow[t]{2}{*}{ Variable } & \multicolumn{4}{|l|}{ Statin Use } & \multirow[t]{2}{*}{ p Value* } \\
\hline & None $(n=3044)$ & $>0$ to $25 \%(n=135)$ & $>25$ to $75 \%(n=355)$ & $>75 \%(n=1748)$ & \\
\hline Age at HF diagnosis & $73.57 \pm 11.38$ & $69.99 \pm 10.81$ & $68.59 \pm 11.13$ & $70.39 \pm 10.03$ & $<0.001$ \\
\hline Follow-up time (days) ${ }^{\dagger}$ & $919.37 \pm 504.18$ & $1107.28 \pm 489.18$ & $1135.08 \pm 519.59$ & $1116.79 \pm 488.11$ & $<0.001$ \\
\hline Male & $2981(97.9 \%)$ & $132(97.8 \%)$ & $348(98.0 \%)$ & $1725(98.7 \%)$ & 0.293 \\
\hline All-cause mortality & $1135(37.3 \%)$ & $32(23.7 \%)$ & $64(18.0 \%)$ & $340(19.5 \%)$ & $<0.001$ \\
\hline \multicolumn{6}{|l|}{ Medications ${ }^{\ddagger}$} \\
\hline ACE & $85.34 \pm 24.56$ & $74.29 \pm 32.68$ & $78.45 \pm 24.70$ & $89.26 \pm 19.40$ & $<0.001$ \\
\hline ARB & $86.40 \pm 23.85$ & $81.14 \pm 32.00$ & $86.50 \pm 15.94$ & $84.96 \pm 25.88$ & 0.152 \\
\hline ASA & $73.23 \pm 32.03$ & $42.71 \pm 34.59$ & $69.31 \pm 31.77$ & $75.14 \pm 31.12$ & $<0.001$ \\
\hline Beta Blocker & $84.32 \pm 24.04$ & $72.79 \pm 33.44$ & $78.68 \pm 24.00$ & $89.70 \pm 16.81$ & $<0.001$ \\
\hline Spironolactone & $83.07 \pm 25.42$ & $72.19 \pm 34.74$ & $78.29 \pm 25.37$ & $84.81 \pm 25.30$ & 0.010 \\
\hline \multicolumn{6}{|l|}{ Comorbid Conditions } \\
\hline Atrial Fibrillation & $1125(37.0 \%)$ & $50(37.0 \%)$ & $109(30.7 \%)$ & $602(34.4 \%)$ & 0.064 \\
\hline Cerebrovascular Disease & $329(10.8 \%)$ & $21(15.6 \%)$ & $31(8.7 \%)$ & $183(10.5 \%)$ & 0.178 \\
\hline Connective Tissue Disease & $113(3.7 \%)$ & $4(3.0 \%)$ & $11(3.1 \%)$ & $65(3.7 \%)$ & 0.909 \\
\hline Coronary Heart Disease & $1331(43.7 \%)$ & $78(57.8 \%)$ & $217(61.1 \%)$ & $1188(68.0)$ & $<0.001$ \\
\hline Dementia & 217 (7.1\%) & $5(3.7 \%)$ & $9(2.5 \%)$ & $55(3.1 \%)$ & $<0.001$ \\
\hline Depression & $508(16.7 \%)$ & $22(16.3 \%)$ & $66(18.6 \%)$ & $285(16.3 \%)$ & 0.771 \\
\hline Diabetes & $901(29.6 \%)$ & $51(37.8 \%)$ & $136(38.3 \%)$ & $693(39.6 \%)$ & $<0.001$ \\
\hline Hemorrhagic Stroke & $11(0.4 \%)$ & $0(0.0 \%)$ & $0(0.0 \%)$ & $5(0.3 \%)$ & 0.604 \\
\hline HIV & $1(0.0 \%)$ & $0(0.0 \%)$ & $0(0.0 \%)$ & $0(0.0 \%)$ & 0.865 \\
\hline Hyperlipidemia & $752(24.7 \%)$ & $85(63.0 \%)$ & $238(67.0 \%)$ & $1257(71.9 \%)$ & $<0.001$ \\
\hline Hypertension & $2069(68.0 \%)$ & $102(75.6 \%)$ & $250(70.4 \%)$ & $1327(75.9 \%)$ & $<0.001$ \\
\hline Kidney Disease & $233(7.7 \%)$ & $18(13.3 \%)$ & $23(6.5 \%)$ & $135(7.7 \%)$ & 0.081 \\
\hline Liver Disease & $94(3.1 \%)$ & $4(3.0 \%)$ & $3(0.8 \%)$ & $20(1.1 \%)$ & $<0.001$ \\
\hline Lung Disease & $1265(41.6 \%)$ & $48(35.6 \%)$ & $131(36.9 \%)$ & $613(35.1 \%)$ & $<0.001$ \\
\hline Malignancy & $484(15.9 \%)$ & $16(11.9 \%)$ & $48(13.5 \%)$ & $198(11.3 \%)$ & $<0.001$ \\
\hline Peptic Ulcer Disease & $91(3.0 \%)$ & $4(3.0 \%)$ & $14(3.9 \%)$ & $44(2.5 \%)$ & 0.499 \\
\hline Peripheral Arterial Disease & $307(10.1 \%)$ & $15(11.1 \%)$ & $44(12.4 \%)$ & $242(13.8 \%)$ & 0.001 \\
\hline Sudden Cardiac Death & $0(0.0 \%)$ & $0(0.0 \%)$ & $0(0.0 \%)$ & $0(0.0 \%)$ & - \\
\hline
\end{tabular}

Data are presented as mean \pm SD or numbers (\%).

* p Values for omnibus tests across the 4 groups.

$\mathrm{ACE}=$ angiotensin converting enzyme inhibitors; $\mathrm{ARB}=$ angiotensin receptor blockers; $\mathrm{ASA}=$ acetylsalicylic acid; $\mathrm{HF}=\mathrm{heart}$ failure; HIV $=$ human immunodeficiency virus.

+ Number of days in study following heart failure diagnosis.

* Number of veterans on each medication differed by statin use stratification. 


\section{References}

[1] Torre-Amione G, Kapadia S, Benedict C, Oral H, Young JB, Mann DL. Proinflammatory cytokine levels in patients with depressed left ventricular ejection fraction: a report from the Studies of Left Ventricular Dysfunction (SOLVD). J Am Coll C ardiol 1996;27:1201-6.

[2] Go AS, Lee WY, Yang J, Lo JC, Gurwitz JH. Statin therapy and risks for death and hospitalization in chronic heart failure. JAMA 2006;296:2105-11.

[3] Keith M, Geranmayegan A, Sole MJ, et al. Increased oxidative stress in patients with congestive heart failure. J Am Coll Cardiol 1998;31:1352-6.

[4] Trochu JN, Mital S, Zhang X, et al. Preservation of NO production by statins in the treatment of heart failure. Cardiovasc Res 2003;60:250-8.

[5] Hattori T, Shimokawa H, Higashi M, et al. Long-term inhibition of Rho-kinase suppresses left ventricular remodeling after myocardial infarction in mice. Circulation 2004;109:2234-9.

[6] Indolfi C, DiLorenzo E, Perrino C, et al. Hydroxymethylglutaryl coenzyme A reductase inhibitor simvastatin prevents cardiac hypertrophy induced by pressure overload and inhibits p21ras activation. Circulation 2002;106: 2118-24.

[7] Horiuchi M, Cui TX, Li Z, Li JM, Nakagami H, Iwai M. Fluvastatin enhances the inhibitory effects of a selective angiotensin II type 1 receptor blocker, valsartan, on vascular neointimal formation. Circulation 2003;107:106-12.

[8] Hanna IR, Heeke B, Bush $\mathrm{H}$, et al. Lipid-lowering drug use is associated with reduced prevalence of atrial fibrillation in patients with left ventricular systolic dysfunction. Heart Rhythm 2006;3:881-6.

[9] Vyas AK, Guo H, Moss AJ, et al. Reduction in ventricular tachyarrhythmias with statins in the Multicenter Automatic Defibrillator Implantation Trial (MADIT)-II. Am Coll Cardiol 2006;47:769-73.

[10] Adam O, Frost G, Custodia F, et al. Role of Rac1 GTPase activation in atria fibrillation. J Am Coll Cardiol 2007;50:359-67.

[11] Appelkvist EL, Edlund C, Löw P, Schedin S, Kalén A, Dallner G. Effects of inhibitors of hydroxymethylglutaryl coenzyme A reductase on coenzyme Q and dolichol biosynthesis. Clin Investig 1993;71:S97-S102.

[12] Moosmann B, Behl C. Selenoprotein synthesis and side-effects of statins. Lancet 2004;363:892-4

[13] Laufs U, Wassmann S, Schackmann S, Heeschen C, Böhm M, Nickenig G. Beneficial effects of statins in patients with non-ischemic heart failure. Z Kardiol 2004;93: 103-8.

[14] Sola S, Mir MQS, Lerakis S, Tandon N, Khan BV. Atorvastatin improves left ventricular systolic function and serum markers of inflammation in nonischemic heart failure. J Am Coll Cardiol 2006;47:332-7.
[15] Mozaffarian D, Minami E, Letterer RA, Lawler RL, McDonald GB, Levy WC. The effects of atorvastatin $(10 \mathrm{mg})$ on systemic inflammation in heart failure. Am J Cardiol 2005:96:1699-704.

[16] Wojnicz R, Wilczek K, Howalany-Kozielaska E, et al. Usefulness of atorvastatin in patients with heart failure due to inflammatory dilated cardiomyopathy and elevated cholesterol levels. Am J Cardiol 2006;97:899-904

[17] Node K, Fujita M, Kitakaza M, Hori M, Liao JK. Short-term statin therapy improves cardiac function and symptoms in patients with idiopathic dilated cardiomyopathy. Circulation 2003;108:839-43.

[18] Foody JM, Shah R, Galusha D, Masoudi FA, Havranek EP, Krumholz HM. Statins and mortality among elderly patients hospitalized with heart failure. Circulation 2006;113:1086-92.

[19] Mozaffarian D, Nye R, Levy WC. Statin therapy is associated with lower mortality among patients with severe heart failure. Am J Cardiol 2004;93:1124-9.

[20] Ramasubbu K, Estep J, White DL, Deswal A, Mann DL. Experimental and clinical basis for the use of statins in patients with ischemic and nonischemic cardiomyopathy. J Am Coll Cardiol 2008;51:415-26.

[21] Fonarow GC, Wright RS, Spencer FA, et al. Effect of statin use within the first 24 hours of admission for acute myocardial infarction on early morbidity and mortality. Am J Cardiol 2005;96:611-6.

[22] Kjekshus J, Apetrei E, Barrios V, et al. Rosuvastatin in older patients with systolic heart failure. N Engl J Med 2007;357:2248-61.

[23] Tavazzi L, Maggioni AP, Marchioli R, et al. Effect of rosuvastatin in patients with chronic heart failure (the GISSI-HF trial): a randomised, double-blind, placebocontrolled trial. Lancet 2008;372:1231-9.

[24] Rinfret S, Behlouli H, Eisenberg MJ, Humphries K, Tu JV, Piloti L. Class effects of statins in elderly patients with congestive heart failure: a population-based analysis. Am Heart J 2008;155:316-23.

[25] Brown SH, Lincoln MJ, Groen PJ, Kolodner RM. VistA-U.S. Department of Veterans. Int J Med Inform 2003;69:135-56.

[26] Allison PD. Missing data. Thousand Oaks, CA: Sage; 2002.

[27] Little RJ, Rubin DA. Statistical analysis with missing data. New York: Wiley; 1987.

[28] Steiger JH, Fouladi RT. R2: a computer program for interval estimation, power calculation, and hypothesis testing for the squared multiple correlation. Behav Res Methods Instrum Comput 1992;24:581-2.

[29] Lee DS, Gona P, Vasan RS, et al. Relation of disease pathogenesis and risk factors to heart failure with preserved or reduced ejection fraction: insights from the Framingham Heart Study of the National Heart, Lung, and Blood Institute. Circulation 2009;119:3070-7.

[30] Fonarow GC. In-hospital initiation of statin therapy in acute coronary syndromes: maximizing the early and long-term benefits. Chest 2005;128:3641-51.

[31] Coats AJ. Ethical authorship and publishing. Int J Cardiol 2009;131:149-50. 